\title{
Modifiable Risk Factors for Cardiovascular Disease in Children with Type 1 Diabetes: Can Early Intervention Prevent Future Cardiovascular Events?
}

\author{
Evgenia Gourgari $^{1,2} \cdot$ Dana Dabelea $^{3} \cdot$ Kristina Rother $^{4}$
}

Published online: 3 November 2017

(C) The Author(s) 2017. This article is an open access publication

\begin{abstract}
Purpose of Review Patients with type 1 diabetes have increased risk for cardiovascular disease.

The purpose of this review is to examine the following:

i) current evidence for subclinical cardiovascular disease (CVD) in children with type 1 diabetes (T1DM)

ii) known modifiable risk factors for CVD and their relationship to subclinical CVD in this population

iii) studies that have addressed these risk factors in order to improve CVD outcomes in children with T1DM
\end{abstract}

This article is part of the Topical Collection on Macrovascular Complications in Diabetes

Evgenia Gourgari

eg685@georgetown.edu

Dana Dabelea

Dana.Dabelea@ucdenver.edu

Kristina Rother

kristinar@intra.niddk.nih.gov

1 Department of Pediatrics, Georgetown University, Washington DC, USA

2 Section on Endocrinology and Genetics, Program on Developmental Endocrinology \& Genetics (PDEGEN) and Pediatric Endocrinology Inter-Institute Training Program, Eunice Kennedy Shriver National Institute of Child Health and Human Development (NICHD), Bethesda, MD, USA

3 Department of Epidemiology, Colorado School of Public Health, University of Colorado Denver, Aurora, CO, USA

4 Section on Pediatric Diabetes and Metabolism, National Institute of Diabetes and Digestive and Kidney Diseases (NIDDK), National Institutes of Health, Bethesda, MD, USA
Recent Findings Subclinical CVD presents in children as increased carotid intima-media thickness, increased arterial stiffness, and endothelial and myocardial dysfunction. Modifiable risk factors for CVD include hyperglycemia, hyperlipidemia, obesity, hypertension, depression, and autonomic dysfunction. Very few randomized controlled studies have been done in children with T1DM to examine how modification of these risk factors can affect their CVD.

Summary Children with T1DM have subclinical CVD and multiple modifiable risk factors for CVD. More research is needed to define how modification of these factors affects the progression of CVD.

Keywords Type 1 diabetes $\cdot$ Children $\cdot$ Youth . Cardiovascular risk $\cdot$ Intervention

\section{Introduction}

Type 1 diabetes (T1DM) affects approximately 3 million people in the USA of whom approximately 200,000 are children [1]. The prevalence of T1DM among pediatric patients has increased between 2001 and 2009 in the USA and worldwide $[2,3]$. Children with T1DM are diagnosed as early as the first year of life, and by the time they are young adults, most of them have been potentially exposed to chronic hyperglycemia for more than two decades. By the time they reach 55 years of age, $35 \%$ of patients with T1D will die from CVD compared to only $8 \%$ of non-diabetic men and $4 \%$ of women [4]. This increased risk for CVD starts in childhood, and it is estimated that $14-45 \%$ of children with T1DM have more than two CVD risk factors $[5 \bullet \bullet]$. Furthermore, children with T1DM already have evidence of subclinical CVD, which can present as increased arterial stiffness, carotid intima-media thickness, and endothelial dysfunction. While most interventions to 
decrease CVD have been studied in adults, few clinical trials have investigated the safety and efficacy of preventive measurements in pediatric patients.

The purpose of this review is to describe:

i)

current evidence for subclinical CVD in children with T1DM

ii) known modifiable risk factors for CVD and their relationship to subclinical CVD in this population and

iii) studies that have addressed these risk factors in order to improve CVD outcomes for children with T1DM

\section{Methods}

We searched PubMed for articles in English using the keywords "type 1 diabetes," "cardiovascular disease," "children," "microalbuminuria," "arterial stiffness," and "depression" as well as "statin," "metformin," "ACE inhibitor," "non-insulin therapies," "lifestyle," and "intervention." We also reviewed manuscripts found in the references of the articles we found via the PubMed search.

\section{Manifestations of Subclinical Cardiovascular Disease}

Major cardiovascular events, such as myocardial infarction and stroke, do not manifest at a young age, and thus, investigators use indirect methods to measure subclinical CVD. The most commonly used methods to detect subclinical CVD are described below.

\section{Carotid Intima-Media Thickness}

One of the methods to investigate CVD is the use of carotid intima-media thickness (CIMT), which has been shown in adults to correlate with future cardiovascular events [6]. Results from studies of CIMT in children with T1DM have been conflicting in some cases, perhaps due to different patient characteristics, sample size and methods used to measure CIMT, but the majority of studies have shown higher CIMT in children with T1DM vs those without diabetes [7, 8]. An older study found higher CIMT in 85 children with T1DM with an average age of $11 \pm 2$ years, $\mathrm{HbA} 1 \mathrm{c} 8.9 \pm 1.4 \%$, and duration of diabetes of $4.4 \pm 3.3$ years compared to healthy controls (HC) $(0.47 \pm 0.04$ versus $0.42 \pm 0.04 \mathrm{~mm}, P<0.0001)$ [8]. Another study also found CIMT to be higher in 52 children with T1DM with an average age of $11.8 \pm 3.1$ years, $\mathrm{HbA1c}$ of $8.6 \pm 1.6 \%$, and duration of diabetes of $4.8 \pm 3.2$ years compared to $47 \mathrm{HC}(0.463 \pm 0.04$ versus $0.441 \pm 0.04 \mathrm{~mm}$, $P=0.001$ ) [9]. In another study, 142 patients with T1DM with an average age of $16 \pm 2.6$ years had higher CIMT when compared to $87 \mathrm{HC}(0.564 \pm 0.005$ versus $0.540 \pm 0.006 \mathrm{~mm}, P=0.002)[10]$. The SEARCH for Diabetes in Youth $(\mathrm{SEARCH})$ study was initiated in 2000 and is funded from the Centers for Disease Control and Prevention and the National Institute of Diabetes and Digestive and Kidney Diseases, in five sites across the USA to improve understanding of childhood diabetes and has recruited only youth with diabetes. SEARCH CVD is an ancillary study conducted at two sites in the USA that collects data on subclinical CVD in youth with diabetes and healthy controls 10-25 years old. The SEARCH for Diabetes in Youth Case-Control (SEARCH CC) is another ancillary study conducted at two sites in the USA that collected clinical and metabolic data on youth with diabetes and healthy controls 10-22 years old. In SEARCH CVD, 402 T1DM patients with an average age of $18.8 \pm 3.3$ years, $\mathrm{HbA} 1 \mathrm{c} 8.9 \pm 1.8 \%$, and duration of diabetes $9.8 \pm 3.8$ years, no difference was seen in the common or internal CIMT when compared to $206 \mathrm{HC}$ $(0.449 \pm 0.073$ versus $0.450 \pm 0.067 \mathrm{~mm}, P=0.82$ and $0.399 \pm 0.078$ versus $0.396 \pm 0.073 \mathrm{~mm}, P=0.68$, respectively), but higher CIMT was found at the level of the bulb of the carotid artery in the T1DM group compared to $\mathrm{HC}$ $(0.461 \pm 0.073$ versus $0.445 \pm 0.069 \mathrm{~mm}, P=0.01)$ [7] Another study showed no difference in CIMT $(0.43 \pm 0.05$ versus $0.42 \pm 0.05, P=0.35$ ) but showed higher aortic intimamedia thickness $(0.57 \pm 0.11$ versus $0.50 \pm 0.07, P<0.001)$ in 66 children with T1DM of average age $14.1 \pm 2.5$ years when compared to HC [11]. More recent studies have also shown higher CIMT in children with T1DM compared to HC [12-14].

\section{Arterial Stiffness}

Another approach to evaluate subclinical CVD is the arterial stiffness. Studies in adults have shown that higher arterial stiffness is associated with increased risk for cardiovascular events $[15,16]$. The carotid-femoral pulse wave velocity (PWV) is considered the gold standard to measure arterial stiffness [17]. Another variable called augmentation index @ 75 beats per minute (AI75) is also used, although AI75 is influenced by peripheral arterial stiffness, heart rate, and reflected waves from peripheral arteries arriving at the heart during systole [17]. Haller et al. reported that 98 children with T1DM with an average HbAlc of $8.41 \pm 1.29 \%$ had higher AI75 compared to $57 \mathrm{HC}$ matched for age, sex, race, and BMI [18]. In the SEARCH study, 535 youths with T1DM with an average age of $14.6 \pm 3.3$ years and $\mathrm{HbA1c} 8.3 \pm 1.9 \%$ had higher arterial stiffness when compared to 241 healthy controls [19]. Later, the same group reported in the SEARCH CVD study 402 adolescents and young adults with T1DM with an average age of $18.8 \pm 3.3$ years, $\mathrm{HbA} 1 \mathrm{c} 8.9 \pm 1.8 \%$, and duration of T1DM $9.8 \pm 3.8$ years had higher pulse wave 
velocity and AI75 compared to 206 healthy controls in a cross-sectional study [20]. Another study found higher PWV among 72 children with T1DM with an average age of $12.3 \pm 1.6$, HbAlc $8.6 \pm 1.9 \%$, and diabetes duration of $3.9 \pm 2.6$ years when compared to $77 \mathrm{HC}$. In a different study that used brachial-ankle pulse wave velocity as an index of arterial stiffness, no difference was seen among 87 children with T1DM with median HbA1c 9.1\% and duration of diabetes 5.1 years compared to $21 \mathrm{HC}$ [21]. Similar results were also seen in a recent study with 199 youths with T1DM compared to $178 \mathrm{HC}$ [22].

\section{Endothelial Dysfunction}

Endothelial dysfunction (ED) is another surrogate marker of subclinical CVD which has been linked to increased CVD events and can be measured by flow-mediated dilation, usually of the brachial artery [23]. Multiple studies have shown worse ED in children with T1DM [24-31], and we will only describe a few of them. A study found greater ED measured by flow-mediated dilation (FMD) among 21 pre-adolescent children with T1DM with an average age of $8.3 \pm 0.3$ years old, HbA1c of $8.0 \pm 2.0 \%$, and diabetes duration of $4.3 \pm 0.4$ years when compared to 15 age matched $\mathrm{HC}$ ( $7.1 \pm 0.8 \%$ versus $9.8 \pm 1.1 \%, P=0.04)$ [32]. Another study showed similar results with 23 children with T1DM with an average age of $14.6 \pm 1.75$ years, $\mathrm{HbAlc} 8.3 \pm 1.6 \%$, and diabetes duration of $5.8 \pm 3.6$ years when compared to 23 $\mathrm{HC}$ measuring the ED with peripheral artery tonometry at the distal phalanges of the hand $(1.78 \pm 0.4$ versus $2.06 \pm 0.4, P=0.02$ ) [25]. A more recent study also showed more ED measured with FMD among 30 children with T1DM with an average age of $11.1 \pm 3.8$ years, $\mathrm{HbA} 1 \mathrm{c} 9.7 \pm 2.2 \%$, and duration of diabetes $3.9 \pm 0.6$ years when compared to 30 $\mathrm{HC}(4.60 \pm 2.13 \%$ versus $9.31 \pm 2.29 \%, P<0.001)[26]$.

\section{Myocardial Dysfunction}

Investigation of myocardial function using echocardiography has also shown increased subclinical CVD in children with T1DM with impaired diastolic dysfunction and left ventricular hypertrophy when compared to HC [22, 26, 33-35]. Diastolic dysfunction was worst in T1DM adolescents compared to HC (early peak velocity/atrial filling velocity (E/A) ratio $1.45 \pm 0.19$ versus $1.85 \pm 0.34, P<0.001$ ) [26]. Adolescents with T1DM have smaller left ventricle end-systolic dimension $(2.90 \pm 0.32$ versus $2.95 \pm 0.33, P=0.0032)$ and other left ventricular myocardial deformation indices [22].

In summary, the above studies indicate that children with T1DM have evidence of subclinical CVD even at this very young age. The main risk factors that contribute to high CVD risk in children with T1DM are described below.

\section{Risk Factors for Cardiovascular Disease}

\section{Hyperglycemia}

Data from the Diabetes Control and Complications Trial (DCCT) that has the longest follow-up (30 years) of adult patients with T1DM have shown that hyperglycemia as assessed by mean HbAlc correlated significantly with the longitudinal changes in all of the traditional CVD risk factors [36]. In fact, the strongest longitudinal associations were among time-dependent triglycerides and LDL Cholesterol $($ LDL-C) $(\beta$-estimates $5.86 \pm 0.39, P<0.0001$ and $2.65 \pm 0.23, P<0.0001)$ with time-dependent HbA1c [36]. More importantly, a recent study using multivariate models assessed the association of traditional and novel risk factors - such as hypertension, hyperglycemia defined by average $\mathrm{HbA1c}$, duration of diabetes, nephropathy, hypoglycemic events, hyperlipidemia, family history of diabetes, and smoking - with major atherosclerotic cardiovascular events in the DCCT cohort and found that HbAlc is an extremely important risk factor for major cardiovascular events, and less important only to age $[37 \bullet \bullet]$.

In pediatric studies, we have seen similar results from cross-sectional and retrospective studies, indirectly assessing the effect of hyperglycemia on established CVD risk factors such as the LDL-C. In the SEARCH study, there were significantly higher levels of total cholesterol, LDL-C, triglycerides, and non-HDL-C with higher hemoglobin A1c among 1680 children with T1DM, but no association was seen between glycemia and HDL-C [38]. Poor glycemic control was associated with high non-HDL and total cholesterol among 682 children with T1DM seen at Barbara Davis Center for Childhood Diabetes [39]. In another retrospective cohort study of 572 youths with T1DM followed longitudinally for a median of 9.3 years, HbA1c modestly affected LDL-C and non-HDL cholesterol [40].

In the SEARCH CVD study, adjustment for HbA1c eliminated the differences in CIMT between T1DM and HC, suggesting that the differences in CIMT are attributable to poor glycemic control [7]. A correlation of CIMT and HbA1c has also been found in other studies [9, 41].

In SEARCH CVD, 298 youths with T1DM with an average age 14.5 years and duration of diabetes 4.8 years had two measurements of arterial stiffness conducted 5 years apart [42]. Authors found that worsening glycemic control was associated with increased arterial stiffness over time [42]. In a cross-sectional evaluation of arterial stiffness among 535 subjects with T1DM and $241 \mathrm{HC}$, the presence of T1DM status was associated with higher arterial stiffness although the $\mathrm{HbA} 1 \mathrm{c}$ was not included in the regression model in this manuscript [19].

The relationship of poor glycemia and endothelial dysfunction, high circulating endothelial cells — which are markers of 
endothelial cell damage - was correlated with $\mathrm{HbAlc}$ in the study by Eltayeb et al. [26]. Another recent study looked at the endothelial dysfunction assessed with skin microvascular perfusion in 181 youths with T1DM and found that HbAlc was an independent determinant of microvascular perfusion [28].

\section{Hyperlipidemia}

Previous studies have shown that approximately $15 \%$ of children with T1DM have high cholesterol, in particular LDL Cholesterol, which is a well-established risk factor for CVD [39, 43, 44••]. In another study published by the SEARCH for Diabetes in Youth Case-Control (SEARCH CC) study, 512 children with T1DM with an average duration of diabetes of 4.2 years had higher small dense LDL particles $(P<0.001$ for children with $\mathrm{HbA1C} \geq 7.5 \%)$ and higher Apolipoprotein $\mathrm{B}(\mathrm{ApoB})(P<0.0001)$ compared to 188 healthy controls [43]. ApoB is a marker of the sum of atherogenic lipoproteins (LDL cholesterol and VLDL cholesterol) because all atherogenic lipoproteins carry the ApoB molecule [45]. Interestingly, the small dense LDL cholesterol and the Apo$B$ were higher in T1DM patients irrespective of their glycemic control, indicating they could be used as better markers for stratifying CVD risk in this population [43]. A recent study investigated further the role of apolipoprotein-B in CVD risk in 267 adolescents with T1DM who had at least 5 years duration of diabetes and an average HbAlc $8.9 \pm 1.6 \%$. They found that patients with high Apo-B had significantly higher arterial stiffness (measured by PWV), which again suggests that the addition of Apo-B can be a useful tool for stratifying the CVD risk in children with T1DM, potentially better than the traditional lipid panel [45]. In the study by Rodriguez et al., LDL-C was independently associated with CIMT [9].

\section{Obesity, Insulin Resistance, and Lack of Exercise}

Contrary to the typical clinical picture of a thin patient with T1DM, obesity is very common today in children with T1DM. Based on baseline data in the T1D Exchange registry obtained from 5529 adolescents with T1D with an average age of $15.4 \pm 1.4$ years and $\mathrm{HbA} 1 \mathrm{c} 8.7 \pm 1.8 \%$, overweight status was present in $22.9 \%$ and obesity was present in $13.1 \%$ in the overall sample [46]. Obesity was highest among girls (40.8\%) and adolescents of Hispanic/Latino race/ethnicity (46.1\%) [46]. Lower frequency was seen in the European German/ Austrian DPV multicenter survey: $12.5 \%$ of T1DM patients were overweight and $2.8 \%$ were obese among 12,774 patients that were followed prospectively with a mean age of $13.4 \pm 3.9$ and mean diabetes duration of $4.7 \pm 3.0$ years [47]. In the European study, factors that were associated with increased obesity during the course of diabetes were higher insulin doses, female gender, low BMI at diabetes onset, intensified insulin therapy, pubertal diabetes onset, and long duration of diabetes [47]. When data from the two registries were combined, children with T1DM had higher BMI $z$ score than the international and their respective normal national data, indicating that obesity among children with T1DM is a significant problem [48]. This is in accordance with adult data from the DCCT trial, where patients with T1DM who received the higher insulin doses also had increased weight gain and higher total cholesterol and LDL-C, central obesity, insulin resistance, blood pressure, more coronary artery calcifications, and higher CIMT on follow-up, underlying the role of obesity in promoting CVD in patients with T1DM [49].

Obesity is associated with atherogenic lipoproteins in youth with T1DM, which increases their CVD risk [39, 50, 51], and BMI is associated with worsening LDL-C over time [40]. In the SEARCH CVD study, 298 youths with T1DM and an average age of $13.3 \pm 2.9$ years, who had two study visits 5 years apart, BMI was the only modifiable risk factor that predicted CIMT based on a linear regression model [52]. Obesity is associated with arterial stiffness even in children without diabetes [53], and it is not surprising that adiposity was also found to be independently correlated to increased arterial stiffness in the previously mentioned SEARCH CVD study by Shah et al. [20].

Insulin resistance (IR) or low insulin sensitivity is associated with obesity and metabolic syndrome. While traditionally IR (or low insulin sensitivity) has been thought to be part of the pathophysiology of type 2 diabetes, recent evidence suggests that IR is also a feature of T1DM that is present even in lean T1DM, and it is a risk factor for CVD in T1DM [44••, 54, 55]. In fact, studies in adults have shown that patients with T1DM and high IR have more coronary artery calcifications, suggesting a higher CVD risk [56]. Recent studies have also shown that IR can also be present in children with T1DM who have normal BMI, suggesting a different underlying mechanism for IR in T1DM [33]. A recent study showed that children with T1DM have atherogenic lipid profiles with dense LDL-C and HDL-cholesterol that is associated with low insulin sensitivity [57]. The same group by Nadeau et al. also showed that children with T1DM and low insulin sensitivity had impaired functional exercise capacity and that low insulin sensitivity correlated with peak oxygen consumption, a measurement of cardiopulmonary fitness [33]. Another large study investigated the effect of low IS on cardiovascular risk factors among 292 adolescents with T1DM with an average age of $15.4 \pm 2.1$ years, hemoglobin A1c $8.9 \pm 1.6 \%$, and duration of diabetes $8.8 \pm 3.0$ years compared to $89 \mathrm{HC}$ [58]. The authors found that lower IS was associated with worsening CVD risk factors of blood pressure, fasting total, low-density lipoprotein-cholesterol (LDL-C) and high-density lipoprotein-cholesterol (HDL-C), high sensitivity C-reactive protein, and BMI $z$ score [58]. Low insulin sensitivity was also found to be an important risk factor for increased arterial stiffness over time in youth with T1DM in the SEARCH CVD study [59]. 
The American Diabetes Association recommends $60 \mathrm{~min}$ of daily exercise for youth with diabetes; however, only $8 \%$ achieve that goal $[60,61]$. Youth with T1DM tends to exercise less than youth without diabetes, most likely due to fear of hypoglycemia due to insulin [44••, 60]. Studies have shown that youth with T1DM who exercises more have better HbA1c, lipoprotein profile, and blood pressure [60, 62] and can therefore improve their CVD risk. A recent study showed that children with T1DM who were making less than 10,000 steps per day had worst arterial intima-media thickness compared to their peers who were more physically active [63].

\section{Hypertension}

Hypertension is an established risk factor for CVD. The American Diabetes Association recommends a goal of BP that is below the 90th percentile for age and sex in children with T1DM and approximately 4-7\% of children with T1DM have hypertension [44••]. Studies have shown that even though the blood pressure in the office can be normal, children with T1DM can have high nighttime blood pressure and lack the physiologic nocturnal dip in blood pressure, which can be measured with $24 \mathrm{~h}$ ambulatory blood pressure monitor (ABPM) [44••].

Hypertension in children with T1DM in the SEARCH CVD study has been linked to arterial stiffness and CIMT [7, 20, 42]. In a recent study, 52 children and adolescents with an average age of $14.07 \pm 3.03$ years and duration of diabetes $5.13 \pm 2.18$ years had higher ABPM readings compared to 20 $\mathrm{HC}$ and within the study group subjects with an abnormal ABPM reading had significantly higher concentrations of sE-selectin - a marker of endothelial dysfunction - compared with subjects with normal ABPM [29]. Another large study evaluated 24-h ABPM in 159 children with T1DM compared to $100 \mathrm{HC}$ and found that $23.3 \%$ of children with T1DM had hypertension, which is more frequent than what is usually reported as hypertension using office measurements of blood pressure, suggesting that ABPM might be a better tool to detect hypertension at the early stages [41]. Furthermore, authors found that the loss of nocturnal systolic blood pressure dip was a significant predictor of CIMT - along with HbAlc — as previously described by another group [41, 64].

\section{Microalbuminuria}

Microalbuminuria is a marker of diffuse vascular injury but in both adults and adolescents with T1DM, can be a self-limiting reversible condition that often resolves with no intervention or with improvement of glycemic control [5, 65-67]. Studies in adults with T1DM have shown patients with T1DM, and microalbuminuria has increased CVD and mortality risk; however, this may represent the fact that microalbuminuria can be mediated by the presence of other CVD risk factors such as hypertension, hyperlipidemia, and IR [5]. Microalbuminuria can also progress to macroalbuminuria and diabetic kidney disease, which is also an established risk factor of CVD in adults with T1DM [5]. In the T1D Exchange, approximately $4.4 \%$ of the 7549 youths with T1DM had microalbuminuria which was associated with longer duration of diabetes, higher HbA1c, older age, female sex, higher diastolic blood pressure (BP), and lower BMI [68]. Another pediatric study showed that 406 adolescents with T1DM with an average age of $14.1 \pm 1.9$ years and diabetes duration of $6.7 \pm 3.7$ years had evidence of early atherosclerosis based on aortic intima-media thickness when compared to $57 \mathrm{HC}$ and that higher urinary albumin excretion, even within the normal range, was associated with early atherosclerosis in youth with T1DM [69].

\section{Depression}

Depression is common among pediatric patients with T1DM with one large study reporting depressive symptoms in $17 \%$ of patients with T1DM [70]. Depression can play a detrimental role in the adherence to diabetes therapy and in the blood glucose monitoring and indirectly affect CVD risk by worsening hyperglycemia and subsequently lipoprotein profile as well [44••, 71, 72]. The American Diabetes Association recommends to consider screening for depression in children as young as 7 or 8 years old [61].

\section{Autonomic Dysfunction}

While autonomic dysfunction is a sign of diabetic neuropathy, it has a direct effect on cardiovascular health for patients with T1DM because it affects the autonomic function of the heart. Autonomic dysfunction can present with low heart rate variability (HRV), which is associated with a $32-45 \%$ increased risk of cardiovascular events in subjects without established CVD [73]. Youth with T1DM from the SEARCH CVD study had decreased HRV which correlated with increased arterial stiffness [74-76]. Poor glycemic control defined as HbAlc over time appears to be a major determinant of decreased HRV [74, 77].

\section{Preventive Clinical Trials in Youth with T1DM}

\section{Intensive Glycemic Control}

Unfortunately, most youths with T1DM do not meet the ADA guidelines for adequate glycemic control and fail to achieve a glycemic control of $<7.5 \%$ [78]. It is concerning that among adolescents less than $21 \%$ achieve this target [78]. We know from the long-term follow-up of the Diabetes Control and Complications Trial (DCCT) cohort of adults with T1DM that 
improved hyperglycemia can improve significantly the cardiovascular outcomes and that glycemic control is closely correlated with other cardiovascular risk factors $[36,79]$. All the interventions described above improve glycemic control in youth with T1DM; however, it remains a big challenge to implement these interventions in children. Collaborative efforts between health care professionals (pediatric endocrinologists, pediatricians, social workers, dietitians, diabetes educators, psychologists) and family members are needed to overcome the obstacles.

\section{Statin Medications}

The American Diabetes Association recommends a statin medication in children with T1DM and LDL-C $>160$ or $>130 \mathrm{mg} / \mathrm{dl}$ and additional cardiovascular risk factors [61]. This recommendation is based on studies done mainly in adults with T2DM and a few trials in adults with T1DM showing that statins can reduce CVD events in patients with diabetes $[61,80]$. Very few randomized studies have been done in children with T1DM to investigate the effect of statin medications on CVD outcomes. One randomized, doubleblinded, cross-over pilot study of 12 weeks using $20 \mathrm{mg}$ atorvastatin vs placebo showed no improvement on arterial stiffness and endothelial function on primary analysis, but a trend towards improvement in endothelial dysfunction was seen $(P=0.06)$ on a secondary proof of concept analysis [81]. In addition, the authors showed that there was a good efficacy profile with a reduction of $29 \pm 20 \mathrm{mg} / \mathrm{dl}$ after 12 weeks of treatment, and the medication was well tolerated on the short term, without major adverse effects on AST or CPK and only a mild increase on ALT by $4.3 \mathrm{U} / 1$ [81]. Another randomized double-blinded study randomized 42 children with T1DM with average age $15 \pm 0.3$ years, HbAlc $8.8 \pm 0.2 \%$, and diabetes duration $6.8 \pm 0.5$ years to atorvastatin $20 \mathrm{mg}$ daily or placebo for 6 months [82]. Patients were enrolled if they had LDL-C > $100 \mathrm{mg} / \mathrm{dl}$ and BMI $<$ 95th percentile and excluded in they had LDL-C >160 mg/dl [82]. Patients in the atorvastatin group had a baseline $\mathrm{HbAlc}$ that was significantly lower than the $\mathrm{HbAlc}$ of the placebo group but otherwise were not different in terms of their age, sex, race, and Tanner stage. The authors showed again that atorvastatin was overall safe and well-tolerated and one subject developed elevated creatinine kinase, which normalized after discontinuation of the medication [82]. They also reported a significant improvement on LDL-C, total LDL particles, non-HDL particles, and Apo-B. Another effort to initiate a randomized trial using statins in adolescents with T1DM indicated that poor recruitment of eligible youth with T1DM can be a major challenge in the conduct of these trials and collaborative efforts in multicenter trials are needed [83]. Another possible limitation to recruitment is the potential effect of teratogenicity of statins, which may necessitate the need for oral contraceptives in some female adolescents at high risk to become pregnant while using statin medications.

While all the above studies indicate improvement in lipid profile, there have been no long-term pediatric clinical trials to our knowledge investigating the effect of statin medications on measurements of subclinical CVD. One such trial is ongoing and is expected to provide some evidence on this topic in the near future [84].

\section{Insulin Sensitizing and Incretin Mimetic Medications}

Given the emerging role of insulin resistance in CVD risk in youth with T1DM, metformin-which improves insulin resistance-has been used as adjuvant treatment off label by pediatric endocrinologists mainly with the goal of improving glycemia. Recent randomized controlled pediatric studies have failed to demonstrate a significant benefit of metformin in improving glycemic control [85, 86]. A large multicenter double-blind, placebo-controlled randomized clinical trial enrolled 140 overweight/obese adolescents with an average $15.3 \pm 1.7$ years and diabetes duration $7.0 \pm 3.3$ years and treated them with metformin or placebo for 26 weeks [85]. The authors failed to demonstrate improvements in $\mathrm{HbAlc}$ or in the LDL-C, HDL, or total cholesterol; however, metformin decreased total daily dose and measurements of adiposity, in accordance with other similar studies [85, 87].

A systematic review and meta-analysis examined data from 325 patients with T1DM treated with metformin as adjuvant to insulin therapy [86].The authors concluded that metformin has no benefit in improving glycemic control but it can lead to modest reduction in the total daily dose of insulin and the BMI, which suggests that metformin could be helpful in decreasing weight gain associated with insulin use and indirectly improve cardiovascular risk of youth with T1DM [86]. Another study was a 9-month randomized, double-blind, placebo controlled trial of metformin and placebo in 28 children with T1DM [88]. The authors showed no improvements in glycemic control or even in total daily dose; however, they state this could be due to the smaller size of the study [88]. An ongoing clinical trial aims to investigate the effect of metformin directly on CVD measurements such as flow-mediated dilation and carotid and aortic intima-media thickness and will be very informative [89].

Other incretin mimetic medications such as the GLP-1 agonists (exenatide, liraglutide) have been used in adults with T1DM and have shown some potential benefit in terms of improving their cardiovascular health [90]. Exenatide has been found to improve weight, insulin sensitivity, and lipoprotein particles in adults with T1DM [91]. Liraglutide use in adults with T1DM leads to reductions in their hypoglycemic events, total daily insulin dose, and bodyweight [90]. Very limited studies on GLP-1 agonists have been done in youth with T1DM. One small trial using exenatide in eight children 
with T1DM showed decreased total insulin dose and improved post-prandial hyperglycemia; however, the role of exenatide on CVD risk factors was not investigated [92].

Overall, more randomized controlled pediatric trials investigating the CVD effects of insulin sensitizing medications in youth with T1DM are needed [93].

\section{Antihypertensive Medications}

ACE inhibitors and ARBs are the first line treatment options for persistent microalbuminuria and hypertension in youth with T1DM [5••]. In a large database in Netherlands, ACE inhibitors, along with statins, are the most commonly used cardiovascular medications among youth with T1DM [94]. The T1D Exchange trial showed that while $4.4 \%$ of youth with T1DM have microalbuminuria, only $36 \%$ of them are treated with ACE inhibitors [68]. One potential explanation for this could be that microalbuminuria is often transient and some physicians elect the "wait and watch" approach over aggressive treatment. Another barrier is also the teratogenicity of both of these medications that can be problematic for certain adolescents with risky behaviors. Studies in adults with T1DM have shown no benefit in preventing diabetic kidney disease without the evidence of albuminuria or hypertension [61]. Based on previous pediatric studies, we know that ACEinhibitors are effective in reducing persistent micro- and macroalbuminuria [67]; however, how this translates to direct benefit for CVD outcomes in children with T1DM is not known. Results from the ongoing trial AdTID will provide evidence on the impact of ACE inhibitors on CVD outcomes in youth with T1DM [84].

\section{Lifestyle Changes}

American diabetes association recommends lifestyle change as the first line treatment to address high cholesterol, obesity, and hypertension in youth with diabetes [61]. A few randomized trials have looked at the effect of diet and exercise on CVD risk reduction in youth with T1DM. A 6-month prospective cohort trial aimed to promote Mediterranean style diet in 96 adolescents with T1DM using dietary intervention. The authors showed significant improvements with reduction of LDL cholesterol, non-HDL-cholesterol, and total cholesterol: HDL-cholesterol ratios in the intervention group $(P<0.001)$ [95]. Another study from the SEARCH study investigated the CVD effects of the DASH diet which encourages fruits, vegetables, low-fat milk products, whole grains, fish/poultry/nuts, lean red meats, and limited intake of sugar and sweets [96]. Authors found that better DASH diet score was significantly associated with lower HbA1c levels in youth with type 1 diabetes $(\beta=-0.20, P=0.0063)$ and improved blood pressure in youth with T2DM $(\beta=-2.02, P=0.0406)[96]$.
There have been some pediatric clinical trials looking at the effects of exercise on CVD health in youth with T1DM. In the large European database with 23,251 pediatric patients with T1DM, more exercise was associated with better cardiovascular risk profile, such as lower levels of LDL cholesterol $(P<0.005)$ and triglycerides $(P<0.00001)$ and higher levels of HDL cholesterol $(P<0.00001)$ in girls with T1DM while in boys there were differences only for triglycerides $(P<0.0005)$ and HDL cholesterol $(P<0.00001)$. Also, the percentage of patients with elevated diastolic blood pressure was lower in the exercise group $(P<0.005)$ and $\mathrm{A} 1 \mathrm{c}$ was lower in the group of patients that exercised more $(P<0.000001)$ [62]. In an interventional trial, 15 children with T1DM received exercise training three times a week for 12 weeks [97]. After the intervention, the authors found significant improvements in total cholesterol levels $(179.9 \pm 2.6$ versus $164.4 \pm 11.4 \mathrm{mg} / \mathrm{dl}$, $P<0.01)$ and in some parameters of the autonomic dysfunction (LF power and VLF power) [97]. In another study, seven children with T1DM received 18 weeks exercise training program, and at the end of the study, authors found improvements in physical fitness (measured by peak oxygen uptake during running test $P=0.039$ ) and brachial artery endothelial dysfunction (measured by FMD, $P<0.05$ ) [98]. In another trial, 16 subjects with T1DM were randomized to a twice per week combined aerobic and resistance training or regular physical activities for 20 weeks [99]. Authors found that exercise seemed to lower daily insulin requirements $(0.96$ versus $0.90 \mathrm{IU} / \mathrm{kg} /$ day, $P<0.05)$ and improved physical fitness $(P<0.05)$ [99]. A systematic review and meta-analysis of the exercise intervention trials in youth with T1DM analyzed data from 23 studies [100]. Authors concluded that exercise intervention has beneficial effects on $\mathrm{HbAlc}$, BMI, triglycerides, and the total cholesterol [100]. The above studies indicate that exercise can be effective in improving CVD health in youth with T1DM.

\section{Antidepressant Medications}

Depression is associated with poor glycemic control, and treatment with antidepressants is expected to improve control. A 6-month intervention trial with SSRI antidepressants was done in 58 adult patients with insulin-dependent poorly controlled T2DM [101]. That study showed that patients improved their depression and glycemic control and their HbAlc dropped from $8.5 \pm 1.2$ to $7.7 \pm 0.7 \%(P<0.001)$ without major changes in their lipid profile [101]. Other studies have shown deterioration of cardiovascular risk factors in adults treated with antidepressants and suggest aggressive monitoring of CVD risk in diabetic patients treated with antidepressants [102]. Based on the data from the observational German diabetes database, youth with T1DM and depression who were treated with antidepressants had better $\mathrm{HbA} 1 \mathrm{c} \mathrm{com}$ pared to non-treated depressed youth $(71.1$ versus $78.1 \mathrm{mmol} /$ 
$1, P<0.003)$ and a trend towards higher BMI $(P=0.05)[103]$. To our knowledge, a randomized controlled study investigating the effects of antidepressants on CVD risk factors in youth with T1DM has not been yet conducted.

\section{Conclusions}

Children with T1DM have evidence of subclinical CVD early in their life as evidenced by abnormalities in CIMT, arterial stiffness, endothelial dysfunction, and myocardial function. Multiple modifiable risk factors contribute to their increased risk for CVD, such as dyslipidemia, hyperglycemia, obesity, insulin resistance, lack of exercise, depression, and autonomic dysfunction. Limited pediatric randomized trials have been conducted to investigate the effect of improvement of these factors on subclinical CVD, but the results of the available trials are so far encouraging. More research is needed on this topic because addressing modifiable risk factors early in the course of CVD can lead to improved CVD outcomes and decrease future morbidity and mortality.

\section{Compliance with Ethical Standards}

Conflict of Interest Evgenia Gourgari, Dana Dabelea, and Kristina Rother declare that they have no conflict of interest.

Human and Animal Rights and Informed Consent This article does not contain any studies with human or animal subjects performed by any of the authors.

Open Access This article is distributed under the terms of the Creative Commons Attribution 4.0 International License (http:// creativecommons.org/licenses/by/4.0/), which permits unrestricted use, distribution, and reproduction in any medium, provided you give appropriate credit to the original author(s) and the source, provide a link to the Creative Commons license, and indicate if changes were made.

\section{References}

Papers of particular interest, published recently, have been highlighted as:

•- Of major importance

1. CDC. National Diabetes Statistics Report. 2014.

2. Dabelea D, Mayer-Davis EJ, Saydah S, Imperatore G, Linder B, Divers J, et al. Prevalence of type 1 and type 2 diabetes among children and adolescents from 2001 to 2009. JAMA. 2014;311(17):1778-86.

3. Patterson CC, Gyurus E, Rosenbauer J, Cinek O, Neu A, Schober E, et al. Trends in childhood type 1 diabetes incidence in Europe during 1989-2008: evidence of non-uniformity over time in rates of increase. Diabetologia. 2012;55(8):2142-7.

4. Libby P, Nathan DM, Abraham K, Brunzell JD, Fradkin JE, Haffner SM, et al. Report of the National Heart, Lung, and Blood Institute- National Institute of Diabetes and Digestive and Kidney
Diseases working group on cardiovascular complications of type 1 diabetes mellitus. Circulation. 2005;111(25):3489-93.

5.• de Ferranti SD, de Boer IH, Fonseca V, Fox CS, Golden SH, Lavie CJ, et al. Type 1 diabetes mellitus and cardiovascular disease: a scientific statement from the American Heart Association and American Diabetes Association. Diabetes Care. 2014;37(10): 2843-63. This study provides a thorough description of CVD in T1DM.

6. Polak JF, Pencina MJ, Pencina KM, O'Donnell CJ, Wolf PA, D'Agostino RB Sr. Carotid-wall intima-media thickness and cardiovascular events. N Engl J Med. 2011;365(3):213-21.

7. Urbina EM, Dabelea D, D'Agostino RB Jr, Shah AS, Dolan LM, Hamman RF, et al. Effect of type 1 diabetes on carotid structure and function in adolescents and young adults: the SEARCH CVD study. Diabetes Care. 2013;36(9):2597-9.

8. Jarvisalo MJ, Putto-Laurila A, Jartti L, Lehtimaki T, Solakivi T, Ronnemaa T, et al. Carotid artery intima-media thickness in children with type 1 diabetes. Diabetes. 2002;51(2):493-8.

9. Rabago Rodriguez R, Gomez-Diaz RA, Tanus Haj J, Avelar Garnica FJ, Ramirez Soriano E, Nishimura Meguro E, et al. Carotid intima-media thickness in pediatric type 1 diabetic patients. Diabetes Care. 2007;30(10):2599-602.

10. Krantz JS, Mack WJ, Hodis HN, Liu CR, Liu CH, Kaufman FR. Early onset of subclinical atherosclerosis in young persons with type 1 diabetes. J Pediatr. 2004;145(4):452-7.

11. Harrington J, Pena AS, Gent R, Hirte C, Couper J. Aortic intima media thickness is an early marker of atherosclerosis in children with type 1 diabetes mellitus. J Pediatr. 2010;156(2):237-41.

12. El-Samahy MH, Tantawy AA, Adly AA, Habeeb NM, Ismail EA, Hamed GM, et al. Expression of CD4+ CD28null T lymphocytes in children and adolescents with type 1 diabetes mellitus: Relation to microvascular complications, aortic elastic properties, and carotid intima media thickness. Pediatr Diabetes. 2017. https://doi. org/10.1111/pedi.12484.

13. El-Asrar MA, Elbarbary NS, Ismail EA, Bakr AA. Circulating angiopoietin-2 levels in children and adolescents with type 1 diabetes mellitus: relation to carotid and aortic intima-media thickness. Angiogenesis. 2016;19(3):421-31.

14. Pezeshki Rad M, Farrokh D, Vakili R, Omidbakhsh M, Mohammadi M. The association between carotid intima-media thickness and the duration of type 1 diabetes in children. Iran J Pediatr. 2014;24(3):249-54.

15. Mitchell GF, Hwang SJ, Vasan RS, Larson MG, Pencina MJ, Hamburg NM, et al. Arterial stiffness and cardiovascular events: the Framingham Heart Study. Circulation. 2010;121(4):505-11.

16. Vlachopoulos C, Aznaouridis K, Stefanadis C. Prediction of cardiovascular events and all-cause mortality with arterial stiffness: a systematic review and meta-analysis. J Am Coll Cardiol. 2010;55(13):1318-27.

17. Townsend RR, Wilkinson IB, Schiffrin EL, Avolio AP, Chirinos JA, Cockcroft JR, et al. Recommendations for improving and standardizing vascular research on arterial stiffness: a scientific statement from the American Heart Association. Hypertension. 2015;66(3):698-722.

18. Haller MJ, Samyn M, Nichols WW, Brusko T, Wasserfall C, Schwartz RF, et al. Radial artery tonometry demonstrates arterial stiffness in children with type 1 diabetes. Diabetes Care. 2004;27(12):2911-7.

19. Urbina EM, Wadwa RP, Davis C, Snively BM, Dolan LM, Daniels SR, et al. Prevalence of increased arterial stiffness in children with type 1 diabetes mellitus differs by measurement site and sex: the SEARCH for diabetes in youth study. J Pediatr. 2010;156(5):731-7. 7 e1

20. Shah AS, Wadwa RP, Dabelea D, Hamman RF, D'agostino R Jr, Marcovina S, et al. Arterial stiffness in adolescents and young 
adults with and without type 1 diabetes: the SEARCH CVD study. Pediatr Diabetes. 2015;16(5):367-74.

21. Yu MC, Lo FS, Yu MK, Huang WH, Lee F. Arterial stiffness is not increased in teens with early uncomplicated type 1 diabetes mellitus. Eur J Pediatr. 2012;171(5):855-8.

22. Bradley TJ, Slorach C, Mahmud FH, Dunger DB, Deanfield J, Deda L, et al. Early changes in cardiovascular structure and function in adolescents with type 1 diabetes. Cardiovasc Diabetol. 2016;15:31

23. Widlansky ME, Gokce N, Keaney JF Jr, Vita JA. The clinical implications of endothelial dysfunction. J Am Coll Cardiol. 2003;42(7):1149-60.

24. Jarvisalo MJ, Raitakari M, Toikka JO, Putto-Laurila A, Rontu R, Laine S, et al. Endothelial dysfunction and increased arterial intima-media thickness in children with type 1 diabetes. Circulation. 2004;109(14):1750-5.

25. Mahmud FH, Van Uum S, Kanji N, Thiessen-Philbrook H, Clarson CL. Impaired endothelial function in adolescents with type 1 diabetes mellitus. J Pediatr. 2008;152(4):557-62.

26. Eltayeb AA, Ahmad FA, Sayed DM, Osama AM. Subclinical vascular endothelial dysfunctions and myocardial changes with type 1 diabetes mellitus in children and adolescents. Pediatr Cardiol. 2014;35(6):965-74.

27. Ladeia AM, Ladeia-Frota C, Pinho L, Stefanelli E, Adan L. Endothelial dysfunction is correlated with microalbuminuria in children with short-duration type 1 diabetes. Diabetes Care. 2005;28(8):2048-50.

28. Shah AS, Gao Z, Dolan LM, Dabelea D, D'Agostino RB Jr, Urbina EM. Assessing endothelial dysfunction in adolescents and young adults with type 1 diabetes mellitus using a noninvasive heat stimulus. Pediatr Diabetes. 2015;16(6):434-40.

29. Machnica L, Deja G, Polanska J, Czupryniak L, SzymanskaGarbacz E, Loba J, et al. Blood pressure disturbances and endothelial dysfunction markers in children and adolescents with type 1 diabetes. Atherosclerosis. 2014;237(1):129-34.

30. Ciftel M, Ertug H, Parlak M, Akcurin G, Kardelen F. Investigation of endothelial dysfunction and arterial stiffness in children with type 1 diabetes mellitus and the association with diastolic dysfunction. Diab Vasc Dis Res. 2014;11(1):19-25.

31. Glowinska-Olszewska B, Moniuszko M, Hryniewicz A, Jeznach M, Rusak M, Dabrowska M, et al. Relationship between circulating endothelial progenitor cells and endothelial dysfunction in children with type 1 diabetes: a novel paradigm of early atherosclerosis in high-risk young patients. Eur J Endocrinol. 2013;168(2):153-61.

32. Babar GS, Zidan H, Widlansky ME, Das E, Hoffmann RG, Daoud $\mathrm{M}$, et al. Impaired endothelial function in preadolescent children with type 1 diabetes. Diabetes Care. 2011;34(3):681-5.

33. Nadeau KJ, Regensteiner JG, Bauer TA, Brown MS, Dorosz JL, Hull A, et al. Insulin resistance in adolescents with type 1 diabetes and its relationship to cardiovascular function. J Clin Endocrinol Metab. 2010;95(2):513-21.

34. Suys BE, Katier N, Rooman RP, Matthys D, Op De Beeck L, Du Caju MV, et al. Female children and adolescents with type 1 diabetes have more pronounced early echocardiographic signs of diabetic cardiomyopathy. Diabetes Care. 2004;27(8):1947-53.

35. Brunvand L, Fugelseth D, Stensaeth KH, Dahl-Jorgensen K, Margeirsdottir HD. Early reduced myocardial diastolic function in children and adolescents with type 1 diabetes mellitus a population-based study. BMC Cardiovasc Disord. 2016;16:103.

36. Writing Group for the DCCT/EDIC Research Group. Coprogression of cardiovascular risk factors in type 1 diabetes during 30 years of follow-up in the DCCT/EDIC Study. Diabetes Care. 2016;39(9):1621-30.

37.• The Diabetes Control and Complications Trial/Epidemiology of Diabetes, Interventions and Complications (DCCT/EDIC)
Research Group. Risk factors for cardiovascular disease in type 1 diabetes. Diabetes. 2016;65(5):1370-9. This study provides risk factors for CVD in T1DM from the large epidemiologic study DCCT.

38. Petitti DB, Imperatore G, Palla SL, Daniels SR, Dolan LM, Kershnar AK, et al. Serum lipids and glucose control: the SEARCH for diabetes in youth study. Arch Pediatr Adolesc Med. 2007;161(2):159-65.

39. Maahs DM, Maniatis AK, Nadeau K, Wadwa RP, McFann K, Klingensmith GJ. Total cholesterol and high-density lipoprotein levels in pediatric subjects with type 1 diabetes mellitus. J Pediatr. 2005;147(4):544-6.

40. Katz ML, Kollman CR, Dougher CE, Mubasher M, Laffel LM. Influence of $\mathrm{HbAlc}$ and BMI on lipid trajectories in youths and young adults with type 1 diabetes. Diabetes Care. 2017;40(1):30-7.

41. Atabek ME, Akyurek N, Eklioglu BS, Alp H. Impaired systolic blood dipping and nocturnal hypertension: an independent predictor of carotid intima-media thickness in type 1 diabetic patients. J Diabetes Complicat. 2014;28(1):51-5.

42. Dabelea D, Talton JW, D'Agostino R Jr, Wadwa RP, Urbina EM, Dolan LM, et al. Cardiovascular risk factors are associated with increased arterial stiffness in youth with type 1 diabetes: the SEARCH CVD study. Diabetes Care. 2013;36(12):3938-43.

43. Guy J, Ogden L, Wadwa RP, Hamman RF, Mayer-Davis EJ, Liese $\mathrm{AD}$, et al. Lipid and lipoprotein profiles in youth with and without type 1 diabetes: the SEARCH for diabetes in youth case-control study. Diabetes Care. 2009;32(3):416-20.

44.• Maahs DM, Daniels SR, de Ferranti SD, Dichek HL, Flynn J, Goldstein BI, et al. Cardiovascular disease risk factors in youth with diabetes mellitus: a scientific statement from the American Heart Association. Circulation. 2014;130(17):1532-58. This study provides a thorough description of CVD in youth with diabetes.

45. Bjornstad P, Nguyen N, Reinick C, Maahs DM, Bishop FK, Clements SA, et al. Association of apolipoprotein B, LDL-C and vascular stiffness in adolescents with type 1 diabetes. Acta Diabetol. 2015;52(3):611-9.

46. Minges KE, Whittemore R, Weinzimer SA, Irwin ML, Redeker NS, Grey M. Correlates of overweight and obesity in 5529 adolescents with type 1 diabetes: the T1D Exchange Clinic Registry. Diabetes Res Clin Pract. 2017;126:68-78.

47. Frohlich-Reiterer EE, Rosenbauer J, Bechtold-Dalla Pozza S, Hofer SE, Schober E, Holl RW, et al. Predictors of increasing BMI during the course of diabetes in children and adolescents with type 1 diabetes: data from the German/Austrian DPV multicentre survey. Arch Dis Child. 2014;99(8):738-43.

48. DuBose SN, Hermann JM, Tamborlane WV, Beck RW, Dost A, DiMeglio LA, et al. Obesity in youth with type 1 diabetes in Germany, Austria, and the United States. J Pediatr. 2015;167(3): 627-32. e1-4

49. Purnell JQ, Zinman B, Brunzell JD, Group DER. The effect of excess weight gain with intensive diabetes mellitus treatment on cardiovascular disease risk factors and atherosclerosis in type 1 diabetes mellitus: results from the Diabetes Control and Complications Trial/Epidemiology of Diabetes Interventions and Complications Study (DCCT/EDIC) study. Circulation. 2013;127(2):180-7.

50. Vaid S, Hanks L, Griffin R, Ashraf AP. Body mass index and glycemic control influence lipoproteins in children with type 1 diabetes. J Clin Lipidol. 2016;10(5):1240-7.

51. Schwab KO, Doerfer J, Naeke A, Rohrer T, Wiemann D, Marg W, et al. Influence of food intake, age, gender, HbAlc, and BMI levels on plasma cholesterol in 29,979 children and adolescents with type 1 diabetes - reference data from the German diabetes documentation and quality management system (DPV). Pediatr Diabetes. 2009;10(3):184-92. 
52. Shah AS, Dabelea D, Fino NF, Dolan LM, Wadwa RP, D'Agostino $\mathrm{R} \mathrm{Jr}$, et al. Predictors of increased carotid intima-media thickness in youth with type 1 diabetes: the SEARCH CVD Study. Diabetes Care. 2016;39(3):418-25.

53. Cote AT, Phillips AA, Harris KC, Sandor GG, Panagiotopoulos C, Devlin AM. Obesity and arterial stiffness in children: systematic review and meta-analysis. Arterioscler Thromb Vasc Biol. 2015;35(4):1038-44.

54. Dabelea D, D'Agostino RB Jr, Mason CC, West N, Hamman RF, Mayer-Davis EJ, et al. Development, validation and use of an insulin sensitivity score in youths with diabetes: the SEARCH for diabetes in youth study. Diabetologia. 2011;54(1):78-86.

55. Bjornstad P, Snell-Bergeon JK, Nadeau KJ, Maahs DM. Insulin sensitivity and complications in type 1 diabetes: new insights. World J Diabetes. 2015;6(1):8-16.

56. Orchard TJ, Olson JC, Erbey JR, Williams K, Forrest KY, Smithline Kinder L, et al. Insulin resistance-related factors, but not glycemia, predict coronary artery disease in type 1 diabetes: 10-year follow-up data from the Pittsburgh Epidemiology of Diabetes Complications Study. Diabetes Care. 2003;26(5):1374-9.

57. Cree-Green M, Maahs DM, Ferland A, Hokanson JE, Wang H, Pyle L, et al. Lipoprotein subfraction cholesterol distribution is more atherogenic in insulin resistant adolescents with type 1 diabetes. Pediatr Diabetes. 2016;(4):257-65. https://doi.org/10.1111/ pedi.12277.

58. Specht BJ, Wadwa RP, Snell-Bergeon JK, Nadeau KJ, Bishop FK, Maahs DM. Estimated insulin sensitivity and cardiovascular disease risk factors in adolescents with and without type 1 diabetes. J Pediatr. 2013;162(2):297-301.

59. Shah AS, Black S, Wadwa RP, Schmiege SJ, Fino NF, Talton JW, et al. Insulin sensitivity and arterial stiffness in youth with type 1 diabetes: the SEARCH CVD study. J Diabetes Complicat. 2015;29(4):512-6.

60. Angela D, Liese XM, Maahs DM, Jennifer L. Trilk physical activity, sedentary behaviors, physical fitness, and their relation to health outcomes in youth with type 1 and type 2 diabetes:a review of the epidemiologic literature. J Sport Health Sci. 2012;2(2013): $21 \mathrm{e} 38$.

61. American Diabetes Association. Standards of medical care in diabetes - 2017. Diabetes Care. 2017;40 (Suppl 1):S1-S135.

62. Herbst A, Kordonouri O, Schwab KO, Schmidt F, Holl RW, DPV Initiative of the German Working Group for Pediatric Diabetology Germany. Impact of physical activity on cardiovascular risk factors in children with type 1 diabetes: a multicenter study of 23,251 patients. Diabetes Care. 2007;30(8):2098-100.

63. Anderson J, Couper JJ, Mpundu-Kaambwa C, Giles LC, Gent R, Coppin B, et al. An extra 1,000 steps per day relates to improved cardiovascular health in children with type 1 diabetes. Diabetes Care. 2016;39(8):e108-9.

64. Lee SH, Kim JH, Kang MJ, Lee YA, Won Yang S, Shin CH. Implications of nocturnal hypertension in children and adolescents with type 1 diabetes. Diabetes Care. 2011;34(10):2180-5.

65. Galler A, Haberland H, Nake A, Hofer S, Holder M, Raile K, et al. Natural course of untreated microalbuminuria in children and adolescents with type 1 diabetes and the importance of diabetes duration and immigrant status: longitudinal analysis from the prospective nationwide German and Austrian diabetes survey DPV. Eur J Endocrinol. 2012;166(3):493-501.

66. de Boer IH, Rue TC, Cleary PA, Lachin JM, Molitch ME, Steffes $\mathrm{MW}$, et al. Long-term renal outcomes of patients with type 1 diabetes mellitus and microalbuminuria: an analysis of the Diabetes Control and Complications Trial/Epidemiology of Diabetes Interventions and Complications cohort. Arch Intern Med. 2011;171(5):412-20.

67. Salardi S, Balsamo C, Zucchini S, Maltoni G, Scipione M, Rollo $\mathrm{A}$, et al. High rate of regression from micro-macroalbuminuria to normoalbuminuria in children and adolescents with type 1 diabetes treated or not with enalapril: the influence of HDL cholesterol. Diabetes Care. 2011;34(2):424-9.

68. Daniels M, DuBose SN, Maahs DM, Beck RW, Fox LA, Gubitosi-Klug R, et al. Factors associated with microalbuminuria in 7,549 children and adolescents with type 1 diabetes in the T1D Exchange clinic registry. Diabetes Care. 2013;36(9):2639-45.

69. Maftei O, Pena AS, Sullivan T, Jones TW, Donaghue KC, Cameron FJ, et al. Early atherosclerosis relates to urinary albumin excretion and cardiovascular risk factors in adolescents with type 1 diabetes: Adolescent type 1 Diabetes cardio-renal Intervention Trial (AdDIT). Diabetes Care. 2014;37(11):3069-75.

70. de Wit M, Snoek FJ. Depressive symptoms and unmet psychological needs of Dutch youth with type 1 diabetes: results of a websurvey. Pediatr Diabetes. 2011;12(3 Pt 1):172-6.

71. Kongkaew C, Jampachaisri K, Chaturongkul CA, Scholfield CN. Depression and adherence to treatment in diabetic children and adolescents: a systematic review and meta-analysis of observational studies. Eur J Pediatr. 2014;173(2):203-12.

72. McGrady ME, Laffel L, Drotar D, Repaske D, Hood KK. Depressive symptoms and glycemic control in adolescents with type 1 diabetes: mediational role of blood glucose monitoring. Diabetes Care. 2009;32(5):804-6.

73. Hillebrand S, Gast KB, de Mutsert R, Swenne CA, Jukema JW, Middeldorp S, et al. Heart rate variability and first cardiovascular event in populations without known cardiovascular disease: metaanalysis and dose-response meta-regression. Europace. 2013;15(5):742-9.

74. Jaiswal M, Fingerlin TE, Urbina EM, Wadwa RP, Talton JW, D'Agostino RB Jr, et al. Impact of glycemic control on heart rate variability in youth with type 1 diabetes: the SEARCH CVD study. Diabetes Technol Ther. 2013;15(12):977-83.

75. Jaiswal M, Urbina EM, Wadwa RP, Talton JW, D'Agostino RB Jr, Hamman RF, et al. Reduced heart rate variability is associated with increased arterial stiffness in youth with type 1 diabetes: the SEARCH CVD study. Diabetes Care. 2013;36(8):2351-8.

76. Jaiswal M, Urbina EM, Wadwa RP, Talton JW, D'Agostino RB Jr, Hamman RF, et al. Reduced heart rate variability among youth with type 1 diabetes: the SEARCH CVD study. Diabetes Care. 2013;36(1):157-62.

77. Ozgur S, Ceylan O, Senocak F, Orun UA, Dogan V, Yilmaz O, et al. An evaluation of heart rate variability and its modifying factors in children with type 1 diabetes. Cardiol Young. 2014;24(5):872-9.

78. Wood JR, Miller KM, Maahs DM, Beck RW, DiMeglio LA, Libman IM, et al. Most youth with type 1 diabetes in the T1D Exchange Clinic Registry do not meet American Diabetes Association or International Society for Pediatric and Adolescent Diabetes clinical guidelines. Diabetes Care. 2013;36(7):2035-7.

79. Diabetes C, Complications Trial /Epidemiology of Diabetes I, Complications Study Research G. Intensive diabetes treatment and cardiovascular outcomes in type 1 diabetes: the DCCT/EDIC Study 30-year follow-up. Diabetes Care. 2016;39(5):686-93.

80. Cholesterol Treatment Trialists C, Kearney PM, Blackwell L, Collins R, Keech A, Simes J, et al. Efficacy of cholesterollowering therapy in 18,686 people with diabetes in 14 randomised trials of statins: a meta-analysis. Lancet. 2008;371(9607):117-25.

81. Haller MJ, Stein JM, Shuster JJ, Theriaque D, Samyn MM, Pepine $\mathrm{C}$, et al. Pediatric Atorvastatin in Diabetes Trial (PADIT): a pilot study to determine the effect of atorvastatin on arterial stiffness and endothelial function in children with type 1 diabetes mellitus. J Pediatr Endocrinol Metab. 2009;22(1):65-8.

82. Canas JA, Ross JL, Taboada MV, Sikes KM, Damaso LC, Hossain $\mathrm{J}$, et al. A randomized, double blind, placebo-controlled pilot trial of the safety and efficacy of atorvastatin in children with elevated 
low-density lipoprotein cholesterol (LDL-C) and type 1 diabetes. Pediatr Diabetes. 2015;16(2):79-89.

83. Bishop FK, Wadwa RP, Ellis S, Rewers M, Maahs DM. Lessons learned from a lipid lowering trial in adolescents with type 1 diabetes. Int J Pediatr Endocrinol. 2012;2012(1):24.

84. Adolescent type 1 Diabetes cardio-renal Intervention Trial Research G. Adolescent type 1 Diabetes Cardio-renal Intervention Trial (AdDIT). BMC Pediatr. 2009;9:79.

85. Libman IM, Miller KM, DiMeglio LA, Bethin KE, Katz ML, Shah A, et al. Effect of metformin added to insulin on glycemic control among overweight/obese adolescents with type 1 diabetes: a randomized clinical trial. JAMA. 2015;314(21):2241-50.

86. Al Khalifah RA, Alnhdi A, Alghar H, Alanazi M, Florez ID. The effect of adding metformin to insulin therapy for type 1 diabetes mellitus children: A systematic review and meta-analysis. Pediatr Diabetes. 2017. https://doi.org/10.1111/pedi.12493.

87. Nadeau KJ, Chow K, Alam S, Lindquist K, Campbell S, McFann $\mathrm{K}$, et al. Effects of low dose metformin in adolescents with type I diabetes mellitus: a randomized, double-blinded placebo-controlled study. Pediatr Diabetes. 2015;16(3):196-203.

88. Nwosu BU, Maranda L, Cullen K, Greenman L, Fleshman J, McShea N, et al. A randomized, double-blind, placebocontrolled trial of adjunctive metformin therapy in overweight/ obese youth with type 1 diabetes. PLoS One. 2015;10(9): e0137525.

89. Anderson J, Pena AS, Sullivan T, Gent R, D'Arcy B, Olds T, et al. Does metformin improve vascular health in children with type 1 diabetes? Protocol for a one year, double blind, randomised, placebo controlled trial. BMC Pediatr. 2013;13:108.

90. Dejgaard TF, Frandsen CS, Hansen TS, Almdal T, Urhammer S, Pedersen-Bjergaard U, et al. Efficacy and safety of liraglutide for overweight adult patients with type 1 diabetes and insufficient glycaemic control (Lira-1): a randomised, double-blind, placebocontrolled trial. Lancet Diabetes Endocrinol. 2016;4(3):221-32.

91. Sarkar G, Alattar M, Brown RJ, Quon MJ, Harlan DM, Rother KI. Exenatide treatment for 6 months improves insulin sensitivity in adults with type 1 diabetes. Diabetes Care. 2014;37(3):666-70.

92. Raman VS, Mason KJ, Rodriguez LM, Hassan K, Yu X, Bomgaars L, et al. The role of adjunctive exenatide therapy in pediatric type 1 diabetes. Diabetes Care. 2010;33(6):1294-6.

93. Raman VS, Heptulla RA. New potential adjuncts to treatment of children with type 1 diabetes mellitus. Pediatr Res. 2009;65(4): $370-4$.
94. Ahmadizar F, Fazeli Farsani S, Souverein PC, van der Vorst MM, de Boer A, Maitland-van der Zee AH. Cardiovascular medication use and cardiovascular disease in children and adolescents with type 1 diabetes: a population-based cohort study. Pediatr Diabetes. 2016;17(6):433-40.

95. Cadario F, Prodam F, Pasqualicchio S, Bellone S, Bonsignori I, Demarchi I, et al. Lipid profile and nutritional intake in children and adolescents with type 1 diabetes improve after a structured dietician training to a Mediterranean-style diet. J Endocrinol Investig. 2012;35(2):160-8.

96. Barnes TL, Crandell JL, Bell RA, Mayer-Davis EJ, Dabelea D, Liese AD. Change in DASH diet score and cardiovascular risk factors in youth with type 1 and type 2 diabetes mellitus: the SEARCH for Diabetes in Youth Study. Nutr Diabetes. 2013;3:e91.

97. Shin KO, Moritani T, Woo J, Jang KS, Bae JY, Yoo J, et al. Exercise training improves cardiac autonomic nervous system activity in type 1 diabetic children. J Phys Ther Sci. 2014;26(1):111-5.

98. Seeger JP, Thijssen DH, Noordam K, Cranen ME, Hopman MT, Nijhuis-van der Sanden MW. Exercise training improves physical fitness and vascular function in children with type 1 diabetes. Diabetes Obes Metab. 2011;13(4):382-4.

99. D'Hooge R, Hellinckx T, Van Laethem C, Stegen S, De Schepper $\mathrm{J}$, Van Aken S, et al. Influence of combined aerobic and resistance training on metabolic control, cardiovascular fitness and quality of life in adolescents with type 1 diabetes: a randomized controlled trial. Clin Rehabil. 2011;25(4):349-59.

100. Quirk H, Blake H, Tennyson R, Randell TL, Glazebrook C. Physical activity interventions in children and young people with type 1 diabetes mellitus: a systematic review with meta-analysis. Diabet Med. 2014;31(10):1163-73.

101. Radojkovic J, Sikanic N, Bukumiric Z, Tadic M, Kostic N, Babic R. Improvement of glycemic control in insulin-dependent diabetics with depression by concomitant treatment with antidepressants. Med Sci Monit. 2016;22:2133-43.

102. Rubin RR, Peyrot M, Gaussoin SA, Espeland MA, Williamson D, Faulconbridge LF, et al. Four-year analysis of cardiovascular disease risk factors, depression symptoms, and antidepressant medicine use in the Look AHEAD (action for health in diabetes) clinical trial of weight loss in diabetes. Diabetes Care. 2013;36(5): 1088-94.

103. Plener PL, Molz E, Berger G, Schober E, Monkemoller K, Denzer $\mathrm{C}$, et al. Depression, metabolic control, and antidepressant medication in young patients with type 1 diabetes. Pediatr Diabetes. 2015;16(1):58-66. 